\title{
( (i) $\|$

Жданов В.Л.

\section{ВЛИЯНИЕ ИНФОРМАЦИОННОГО И ПОСТИНДУСТРИАЛЬНОГО ОБЩЕСТВА НА КОСМИЧЕСКУЮ ПОЛИТИКУ В ЭПОХУ ГЛОБАЛИЗАЦИИ}

Аннотация: В статье проанализировано влияние теорий информационного и постиндустриального общества на развитие космической политики. Под действиями теорий информационного общества иерархия цฺелей космической политики трансформируется. Приоритетными космическими задачами сегодня являются обеспечение информационного трафика. Анализируются труды таких исследователей в этой области как Д. Белл, Р. Плейкис, Э. Тоффлер. Акиентируется внимание на то, что именно космическую политику можно рассматривать осевой системой политических теорий, проходящей как сквозь концепции индустриализма, так и являющейся отображением теорий не только постиндустриализма, но и информационного общества в целом. Космическая политика не только уже влияет на непосредственный доступ кинформации, но и, может являться элементом цеенуры в весьма недалеком будущем, а проблема доступа к информаџии есть одна из наиболее политически острых. Именно доступ к информации как краеугольное условие свободы-имеет непосредственное отношение на формирование космической политики, что в эпоху глобализации является очень актуальным.

Abstract: This article analyzes the influence of the theories of information and post-industrial society upon the development of space politics. It examines the works of such researches in this field like Daniel Bell, Rimantas Pleikis, and Alvin Toffler. The author emphasizes that the space politics in particular can be viewed as the axis of political theories, which passes through the concept of industrialism, as well as being a reflection of post-industrialism theories and information society as a whole. The space politics affects not only the direct access to information, but can also be an element of censorship in a very near future; but the problem of access to information is one of the most politically sensitive. It is namely the access to information as the cornerstone example of freedom that carries a direct impact on the forming of space politics, which is very relevant in the era of globalization.

Ключевые слова: Политология, космическая политика, космическое сознание, постиндустриальное общество, информационное общество, космические технологии, информация, радиоглуиение, иензура, глобализация.

Keywords: Political sciences, space politics, cosmic consciousness, post-industrial society, information society, space technologies, information, frequency jamming, censorship, globalization.

оявлению термина «постиндустриальное общество» мы обязаны американскому политологу Дэниэлу Беллу (Daniel Bell, 1919) написавшему знаковую во многих отношениях работу «The Coming of Post-Industrial Society» (в русском переводе - «Грядущее постиндустриальное общество»), увидевшую свет в 1973 г. В какой то мере, суммировав экономические показатели, Д. Белл определил новую общественно-политическую реальность, пришедшую на смену индустриальным - де Сен-Симоновским ${ }^{1}$ практикам.

${ }^{1}$ Белл Д. Грядущее постиндустриальное общество. - М., 2004, стр. 6.

1774
Не менее интересной, является работа Д. Белла «Социальные рамки информационного общества», где автор выделяет три аспекта, которые на его взгляд наиболее актуальны для понимания телекоммуникационной революции, перефразируя Д. Белла, аспекты эти следующие:

- трансформация постиндустриального общества в общество услуг;

- примат кодифицированного теоретического знания в контексте технологических инноваций; и, наконец

- $\quad$ интеллектуальная технология как ключевой инструмент системного анализа и теории принятия решений.

\section{4}

(C) NOTA BENE (OOO «НБ-Медиа») www.nbpublish.com 
Казалось бы, космическая политика, интерпретацией которой, в естественно - научном, инженерном измерении является космическая программа - что это, как не некое критическое проявление индустриального вектора развития общества - «венец» индустриализма. И как это соотносится с концепциями Д. Белла, о том, что «индустриальные» достижения - скорее удел цивилизационных доменов, находящихся в позиции «догоняющих». Однако, космическая политика, являясь критичным проявлением идей индустриализма, тем не менее, так же символизирует ту трансформацию общества, которую, в качестве первого критерия выделяет Д. Белл. Более 300 спутников на геостационарной орбите только и служат для того, что бы обеспечивать информационные практики. Внешняя визуализация - в виде стартующих в небо огромных ракет, ошибочно принимаемых общественным мнением за «зерно» космической политики - лишь средство транспортировки технологической платформы для обеспечения бесперебойного трафика информации различного рода - от экологического мониторинга до передачи медийного контента. На наш взгляд, именно космическую политику можно рассматривать осевой системой политических теорий, проходящей как сквозь концепции индустриализма, так и являющейся отображением теорий не только постиндустриализма, но и информационного общества в целом.

Второй аспект - важность кодифицированного знания - так же имеет прямое отношение к космической политике. С технологической точки зрения, космическая политика произрастает из интернациональных источников - работ Р. Годдарда, К. Циолковского, Г. Оберта и многих других, которые не только были понятны друг другу, но и смогли «донести» свои знания до учеников, воплотивших их идеи в жизнь. Кодификация знания при этом была неизбежна, и даже скорее естественна.

Что касается третьего аспекта - технологий системного анализа и теории принятия решения, то достаточно вспомнить этапы развития космической политики - от сугубо военного к вполне информационно-ориентированному. Орбитальный флот не только «перекачивает» информацию, он еще и собирает ее и предает в центры принятия решений. И не важно, идет ли речь об определении координат доставщика пиццы в мегаполисе или о нарождающемся циклоне в Атлантическом океане - именно на основе данной интеллектуальной технологии принимаются решения множеством пользователей на Земле.

Д. Белл так же вводит понятие информационной стоимости: «Когда знание в своей систематической форме вовлекается в практическую переработку (в виде изобретения или организационного усовершенствования), можно сказать, что именно знание, а не труд выступает источником стоимости» 2 .

Именно знание есть база того технологического рывка, который мы могли наблюдать в том числе и в развитие космических программ - от опытов американца Р. Годдарда с первой жидкотопливной ракетой Nell в 1926 г. до полета первого спутника в 1957 г. - если вдуматься, в тридцать один год уложилась своеобразная технологическая эволюция, заказчиком которой выступало общество, правда в лице военных институтов, и которая стала возможна, в том числе, благодаря некому критическому объему знаний накопленных ранее.

Слияние технологий, по мнению Д. Белла так же есть некий отличительный признак постиндустриального общества, и на примере космической политики данный признак легко различим. Практически все космические технологии имеют двойное применение - военное и мирное, или, сформулировав по другому, в каждом измерении космической политики можно различить весь спектр земных технологий. В этом отношении, космические программы вообще были бы не мыслимы без технологического синтеза - космические технологии - это критичная, запредельная форма земных практик. Что бы произвести спутник типа Boeing-702 или даже Ямал-200, сотни специалистов самой разной направленности вовлечены в процесс его «рождения» - химики, физики, математики, инженеры всех уровней и еще множество «носителей» того самого капитала, имя которому - «знание». Д. Белл именует эту социальную страту - носителей знания - «этнос науки»: «...научное сословие - его форма и содержание - является монадой, содержащей в себе прообраз будущего общества»³.

Д. Белл четко определяет информацию как власть дословно: «Информация - это власть» ${ }^{4}$, не уточняя, вводит ли он тем самым новый источник власти вообще или же речь идет о некой разновидности власти - например, журналисты любят называть себя четвертой или пятой

\footnotetext{
2 Белл Д. Социальные рамки информационного общества. // Российский Гуманитарный Интернет-Университет www.i-u. ru // URL: http://www.i-u.ru/biblio/archive/bell newtehnvar/? search $=\%$ e $1 \%$ e $5 \%$ eb\%eb\#st

${ }^{3}$ Белл Д. Грядущее постиндустриальное общество. - М., 2004, стр. 27.

${ }^{4}$ Белл Д. Социальные рамки информационного общества. // Российский Гуманитарный Интернет-Университет www.i-u. ru // URL: http://www.iu.ru/biblio/archive/bell newtehnvar/? search $=\%$ e $1 \%$ e $\%$ eb\%eb\#st (дата обращения 01.12.2009)
} 
DOI: $10.7256 / 1811-9018.2014 .11 .7711$

При цитировании этой статьи сноска на dоі обязательна

\section{Право и политика $11(179) \cdot 2014$}

властью - опуская при этом слово «ветвь». «Доступ к информации есть условие свободы» ${ }^{5}-$ пишет Д. Белл чуть ниже. Получается, что свобода, как одно из важнейших общественных благ напрямую связана с космической политикой, в рамках которой на геостационарной орбите находится флот из трех сотен спутников, каждый из которых способен перекрыть ретранслируемым сигналом до $40 \%$ от поверхности Земли.

При подготовке данной статьи, была прочитана крайне интересная статья литовского исследователя Римантаса Плейкиса «Радиоцензура». Автор данной работы проанализировал уникальный как по объему, так и по значению информационный пласт, имеющий прямое отношение к тому самому «условию свободы», а именно доступу к информации, о котором пишет Д. Белл. Р. Плейкис досконально исследовал феномен «постиндустриального общества» - радиоглушение, как одну из основных практик контроля информационных потоков: «к концу восьмидесятых годов в Советском Союзе было 210-235 центров радиоподавления с парком передатчиков от 2900 до 3500 единиц. В некоторые вечерние часы приходилось одновременно глушить до 7 радиостанций.... годовые расходы на глушение по Советскому Союзу достигали 260 млн рублей, а с обновлением и расширением системы - более 300 млн рублей. В западной печати приводились цифры от 0,4 до 1,2 млрд долларов в год» ${ }^{6}$. Получается, что с одной стороны, разные страны - США, ФРГ, Китай, Югославия и даже Албания тратили определенные средства на финансирование своих радиостанций, а с другой стороны, деньги тратились на «отражение» информационной агрессии или же на «недопущение» своих граждан к иной, отличной от политически корректной информации - выбор варианта предельно субъективен. Р. Плейкис приводит только один факт, когда объектом глушения выступал спутниковый сигнал: «Турция из военной базы возле города Синоп на севере страны на частоте транспондера излучала видео- и звуковые помехи в направлении искусственного спутника Земли, через который на Европу и Ближний Восток шли передачи курдской телестанции «Med TV» из Лондона» $\rangle^{7}$ - то есть, прецедент был - имело место глушение спутникового сигнала. Учитывая то, что 39 стран в разное время так или иначе ограничивали

\footnotetext{
${ }^{5}$ Там же.

${ }^{6}$ Плейкис Р. Радиоцензура. //Информационный портал «Все о радио в России и за рубежом» http://radio.hobby.ru // URL: http:// radio.hobby.ru/glushilka.html

${ }^{7}$ Там же.
}

доступ к информации своим гражданам, и на сегодняшний день некоторые страны продолжают эти практики (например Китай) - развитие технологий глушения спутникового сигнала будет иметь продолжение.

Если говорить о теориях информационного общества, то не представляется возможным обойти стороной работу американского журналиста Элвина Тоффлера 1928 г. «Третья Волна», впервые вышедшую в США в 1980 г. «Самым важным (и неистощимым) сырьем для цивилизации Третьей волны станет информация, включая воображение. Информация приобретет большую ценность, чем когда-либо, и новая цивилизация перестроит систему образования и научных исследований, а кроме того, реорганизует средства массовой информации.... Вместо культурного доминирования нескольких средств массовой информации в цивилизации Третьей волны начнут преобладать интерактивные, демассифицированные средства, обеспечивающие максимальное разнообразие и даже персональные информационные запросы» ${ }^{8}$.

Говоря о космосе, Э. Тоффлер выделяет как минимум три приоритета космической политики: решение энергетических проблем, развитие орбитального производства и, наконец, прямая экспансия в космос. Американский футуролог Э. Тоффлер прямо призывает перейти на новый уровень осмысления - к «космическому сознанию»: «Как Вторая волна породила слой людей, чьи интересы превосходи локальный уровень и становились основой национальной идеологии, так Третья волна порождает группы людей, интересы которых шире, чем национальные. Эти люди становятся носителями формирующейся глобалистской идеологии, которую иногда именуют «планетарным сознанием». Глобализм представляется чем-то большим, нежели идеология, служащая интересам ограниченной группы людей. Национализм говорил от лица нации, глобализм выступает от лица всего мира. И его появление представляется эволюционной необходимостью - ступенью к «космическому сознанию», охватывающему не только Землю, но и Вселенную» ${ }^{9}$. Как говориться, комментарии здесь излишни. Это уже даже ближе к идеям Николая Федорова, особенно с учетом того, что генную инженерию Э. Тоффлер рассматривает как одну из четырех становых отраслей цивилизации Третьей волны.

Таким образом, космическая политика не только уже влияет на непосредственный доступ к информации, но и, возможно, будет являться элементом цензуры в

\footnotetext{
${ }^{8}$ Тоффлер Э. Третья волна. - М.: АСТ, 1999, стр. 273.

${ }^{9}$ Там же, стр. 254-255.
} 
DOI: $10.7256 / 1811-9018.2014 .11 .7711$

При цитировании этой статьи сноска на dоі обязательна

Правовая и политическая мысль

весьма недалеком будущем. Дихотомия - спутникпередатчик идеологически «неправильного» контента - спутник-цензор. В этом отношении, именно доступ к информации как краеугольное условие свободы имеет непосредственное отношение на формирование космической политики не только в настоящий момент, но и будет определять вектор ее развития до тех пор, пока будут вестись так называемые «информационные войны», что в эпоху глобализации является очень актуальным. В этом смысле идеи постиндустриального мира, с его условиями свободы, как базовой ценностью, безусловно, влияют на космические программы, детализируя их под текущие политические задачи: «знания и информация становятся стратегическими ресурсами и агентом трансформации постиндустриального общества. Бурное протекание общественных изменений, особенно когда они, как в данном случае, осуществляются через посредство специфических технологий, с неизбежностью ставит перед обществом сложные политические проблемы ${ }^{10}$ - и проблема доступа к информации есть одна из наиболее политически острых в условиях глобализации.

\section{Библиография:}

1. Белл Д. Грядущее постиндустриальное общество. - М., 2004, стр. 6.

2. Белл Д. Социальные рамки информационного общества. // Российский Гуманитарный Интернет-Университет www.i-u. ru // URL: http://www.i-u.ru/biblio/archive/bell_newtehnvar/? search=\%e1\%e5\%eb\%eb\#st (дата обращения 01.12.2009)

3. Плейкис Р. Радиоцензура. //Информационный портал «Все о радио в России и за рубежом» http://radio.hobby.ru // URL: http://radio.hobby.ru/glushilka.html

4. Тоффлер Э. Третья волна. - М.: АСТ, 1999, стр. 273.

\section{References (transliterated):}

1. Bell D. Gryadushchee postindustrial'noe obshchestvo. - M., 2004, str. 6.

2. Bell D. Sotsial'nye ramki informatsionnogo obshchestva. // Rossiiskii Gumanitarnyi Internet-Universitet www.i-u.ru // URL: http://www.i-u.ru/biblio/archive/bell_newtehnvar/? search=\%e1\%e5\%eb\%eb\#st (data obrashcheniya 01.12.2009)

3. Pleikis R. Radiotsenzura.//Informatsionnyi portal «Vse o radio v Rossii i za rubezhom» http://radio.hobby.ru // URL: http://radio. hobby.ru/glushilka.html

4. Toffler E. Tret'ya volna. - M.: ACT, 1999, str. 273.

\footnotetext{
${ }^{10}$ Белл Д. Социальные рамки информационного общества. // Российский Гуманитарный Интернет-Университет www.i-u. ru // URL: http://www.i-u.ru/biblio/archive/bell_newtehnvar/? search $=\%$ e $1 \% \mathrm{e} 5 \% \mathrm{eb} \% \mathrm{eb} \#$ st
} 